Article

\title{
Correlates of the Intention to Reduce Meat Consumption
}

\author{
Ann Krispenz * $*$ and Alex Bertrams \\ Educational Psychology Lab, Institute of Educational Science, University of Bern, 3012 Bern, Switzerland; \\ alexander.bertrams@edu.unibe.ch \\ * Correspondence: ann.krispenz@edu.unibe.ch
}

Received: 1 May 2020; Accepted: 6 June 2020; Published: 11 June 2020

check for updates

\begin{abstract}
Meat consumption significantly contributes to environmental damage. Thus, a reduction in meat consumption can be regarded as sustainable behavior. Based on the assumptions of the theory of planned behavior, we examined the predictive power of individuals' attitudes, their subjective norm, and perceived behavioral control for their intention to reduce domestic meat consumption. We assessed respective variables in a sample of 256 university students (2015) and 231 employees and university students (2017). Regression analyses revealed that the attitude toward reducing one's own meat consumption was strongly related to the corresponding intention. Furthermore, the subjective norm predicted one's intention to eat less meat, whereas perceived behavioral control did not. Results were similar across both samples (2015 and 2017). The findings imply that sustainable meat consumption is most likely to be achieved by a change in consumers' attitudes.
\end{abstract}

Keywords: theory of planned behavior; meat consumption; attitudes

\section{Introduction}

Meat consumption significantly contributes to environmental damage (e.g., loss of biodiversity) [1]. Thus, reducing one's meat consumption can be regarded as sustainable behavior [2]. From a psychological perspective, the intention to eat less meat can be predicted based on the assumptions of the theory of planned behavior $(\mathrm{TpB})$ [3]. According to the $\mathrm{TpB}$, the formation of a behavioral intention (e.g., the intention to eat less meat in the future) is based on a combination of one's attitude toward the behavior (e.g., aggregated beliefs about the outcomes of eating less meat and evaluations of these outcomes), the subjective norm (e.g., perceived social pressure to eat less meat), and perceived behavioral control (e.g., beliefs about factors that might facilitate or hinder execution of the intention to eat less meat). A vast body of empirical studies supports the validity of the TpB including meta-analytical reviews [4]. There are also a few studies studying $\mathrm{TpB}$ in the context of reducing meat consumption [5,6]. The results showed that one's attitude toward eating less meat contributed the most to individual behavioral intention, whereas subjective norms contributed only a small amount, and perceived behavioral control did not contribute at all. However, in the last few years, dietary styles like veganism have become more popular in western countries [7]. As the internet has become more readily accessible than it was in the 1990s, so has the information it offers members of the general public, especially information regarding the environmental and health repercussions of meat consumption [8]. As a consequence of these trends, perceived social pressure (i.e., the subjective norm) to eat less meat might also have increased accordingly. Thus, in the present study, we investigated the predictive power of TpB for one's intention to eat less meat using more recent data (2015 and 2017) from two surveys conducted in Switzerland. In line with previous research $[5,6]$, we assumed that the individuals' intention to eat less meat would be predicted most strongly by their respective attitude but not by their perceived behavioral control. However, due to recent dietary trends (e.g., veganism) 
and heightened accessibility of information about the damaging effects of meat, we also expected a heightened influence of individuals' subjective norms.

\section{Materials and Methods}

\subsection{Participants}

Based on the recommendations of Tabachnick and Fidell [9], we aimed for a minimum sample size of $N=104+3$ (number of predictors) assuming a medium-sized relationship between the predictors and the criterion $(\alpha=0.05, \beta=0.20)$. For Survey 1 in 2015, 325 students of two German-Swiss universities were approached, 257 of whom (i.e., $79 \%$ ) indicated that they ate meat (i.e., were not vegetarian or vegan). One student who indicated to not fully understand German was excluded from the data analysis. Ultimately, data of 256 students $\left(M_{\text {age }}=25.53\right.$ years, $S D_{\text {age }}=4.52,59.8 \%$ women $)$ were assessed. For Survey 2 in 2017, 248 individuals in Switzerland were approached. Of these individuals, 231 (i.e., 93\%) $\left(M_{\mathrm{age}}=31.32, S D_{\mathrm{age}}=12.21,59.7 \%\right.$ women) indicated they ate meat. Out of these 231 participants, 129 individuals (55.8\%) indicated they were either an employee or self-employed, while 94 individuals reported being a student (40.7\%). The eight remaining individuals (3.5\%) stated they were currently neither a student nor employed.

\subsection{Procedure}

The survey included only the participants' self-reports via questionnaires and did not include any experimental or other active intervention by the researchers. We carefully ensured that both surveys were conducted in line with the ethical guidelines of the Swiss Psychological Society (SPS) and the American Psychological Association (APA). For both surveys, the same materials were used. Both surveys exclusively made use of anonymized questionnaires. Survey 1 was carried out using tablet computers. Survey 2 was conducted online. The link to the second survey was distributed via email lists. The surveys took place in August of 2015 and in September/ October of 2017. Before either survey, participants were informed about the research object, the voluntary nature of their participation, and the anonymity of data collection. After giving informed consent, participants were asked to indicate if they were vegans, vegetarians, or meat-eaters. Since the surveys were designed to investigate the individuals' intention to eat less meat, vegans and vegetarians were thanked and dismissed. Meat-eating individuals were asked to indicate their weekly average meat consumption and were presented with a short section taken from the Environment Report Switzerland 2015 [10] to ensure a standardized level of prior knowledge about the damaging effects of meat consumption for all participants:

Private household consumption plays a key role in rising global resource consumption and the continuing high levels of environmental pollution. At $28 \%$, nutrition contributes most to the environmental impact generated by consumers. Meat and other animal products are the main factors here. They cause almost half of this impact as their production requires a lot of energy for cultivating the soil. Also, they require the use of plant protection products, fertilizers and intensively farmed agricultural land.

Subsequently, TpB variables were assessed. As suggested by Ajzen [11], items were presented in a random order. Afterwards, participants gave information about their age, sex, education/employment, and language ability. Participants were not compensated.

\subsection{Measures}

\subsubsection{Eating Style}

To assess their eating style, participants were asked to indicate if they were eating (1) no animal products at all, (2) no meat but animal products, or (3) meat products (e.g., roasted meats, sausages, 
cold cuts). If participants reported to eat meat, they were additionally asked the average number of days per week they were eating meat.

\subsubsection{TpB Variables}

The participants' ratings of TpB variables were assessed with 18 items, which were developed in accordance with Ajzen's [11] comprehensive conceptual and methodological considerations for the development of $\mathrm{TpB}$ questionnaires. This approach was successfully used in previous studies analyzing TpB in the context of reducing meat consumption [5,6]. As recommended by Ajzen, our first step was to specifically define the behavior of interest as "eating less meat at least one day a week". We then used the item stem formulations provided by Ajzen to assess the theory's major variables (i.e., attitude, subjective norm, perceived behavioral control, and intention) regarding the behavior of interest. Furthermore, in line with Ajzen's approach, ratings were made using 7-point scales with two extreme response categories from -3 (e.g., extremely unlikely) to +3 (e.g., extremely likely) with one neutral category (0). Prior to the data analyses, all ratings were inverted to 7-point scales ranging from 1 (e.g., extremely unlikely) to 7 (e.g., extremely likely) with low ratings always expressing low values (e.g., a low subjective norm to reduce meat consumption) and high ratings mirroring high values (e.g., a high subjective norm to reduce meat consumption).

To assess their attitude toward eating less meat, participants were asked to complete a statement ("For me, in the future, eating meat at least one day less a week would be...") using semantic differentials and five 7-point rating scales. Two of these differentials related to instrumental aspects of eating less meat: (1) -3 (harmful) to +3 (beneficial), and (2) -3 (worthless) to +3 (valuable). Two other differentials focused on experiential aspects of eating less meat: (3) -3 (pleasant) to +3 (unpleasant), and (4) -3 (enjoyable) to +3 (unenjoyable). The fifth differential captured the overall evaluation of eating less meat: (5) -3 (good) to +3 (bad). A mean attitude score was calculated with high scores indicating a positive attitude toward eating less meat. The items showed good internal consistencies (Cronbach's $\alpha$ Study $1=0.88$, Study $2=0.82$ ).

The subjective norm toward eating less meat was assessed with six items. The first three items had an injunctive quality: (1) "Most people who are important to me think that I should eat meat at least one day less per week in the future" ( -3 (strong agreement) to +3 (strong disagreement)); (2) "It is expected of me that I will eat meat at least one day less per week in the future" ( -3 (extremely likely) to +3 (extremely unlikely)); and (3) "The people in my life whose opinions I value would ( -3 (approve) to +3 (disapprove)) of me eating meat at least one day less per week in the future." The other three items focused on descriptive norms: (4) "Most people who are important to me will eat meat at least one day less per week in the future" ( -3 (absolutely true) to +3 (absolutely false)); (5) "The people in my life whose opinions I value will ..." ( -3 (eat meat at least one day less per week in the future) to +3 (not eat meat at least one day less per week in the future)); and (6) "Many people like me will eat meat at least one day less per week in the future" ( -3 (extremely unlikely) to +3 (extremely likely)). A mean subjective norm score was calculated with high scores indicating a high subjective norm toward eating less meat. The items showed satisfactory internal consistencies (Cronbach's $\alpha$ Study $1=0.68$, Study $2=0.61$ ).

Perceived behavioral control was assessed with four items: (1) "For me, to eat meat at least one day less a week in the future would be ... " (-3 (impossible) to +3 (possible)); (2) "If I wanted, I could eat meat at least one day less a week in the future" ( -3 (definitely true) to +3 (definitely untrue)); (3) "How much control do you think you have over eating meat at least one day less a week in the future?" ( -3 (no control) to +3 (complete control)); and (4) "It is mostly up to me whether or not I eat meat at least one day less a week in the future" ( -3 (strongly agree) to +3 (strongly disagree)). A mean perceived behavioral control score was calculated with high scores indicating a high perceived control toward eating less meat. The items showed low internal consistencies (Cronbach's $\alpha$ Study $1=0.58$, Study $2=0.45$ ). 
The intention to eat less meat was assessed with three items: (1) "In the future, I intend to eat meat at least one day less per week" ( -3 (extremely unlikely) to +3 (extremely likely)); (2) "In the future, I will try to eat meat at least one day less per week" ( -3 (definitely true) to +3 (definitely untrue)); and (3) "In the future, I plan to eat meat at least one day less per week" (-3 (strongly disagree) to +3 (strongly agree)). A mean intention score was calculated with high scores indicating a high intention to eat less meat. The items showed good internal consistencies (Cronbach's $\alpha$ Study $1=0.86$, Study $2=0.85$ ).

\section{Data Analyses}

In the present study, we investigated the predictive power of the TpB for the intention to eat less meat using data from two surveys conducted in Switzerland in 2015 and 2017. In line with previous research [5,6], we assumed individuals' intention to eat less meat to be predicted most strongly by their respective attitude but not by their perceived behavioral control. In contrast to similar studies from the 1990s, we expected a heightened influence of individuals' subjective norm due to recent trends. To test our hypotheses, we conducted hierarchical linear regression analyses using the pooled data of both surveys (Table 1 ) and the mean scores for all $\mathrm{TpB}$ variables. This approach was chosen because it mirrors the data analysis strategy of former studies investigating individuals' intention to eat less meat $[5,6]$, thus ensuring the comparability of the results of our analysis with those of former studies.

\subsection{Preliminary Analyses}

To meet the prerequisites of linear regression analyses, we checked for potential outliers and extreme collinearity. We also tested for normality of our data. Univariate outliers were defined as scores more than three standard deviations beyond the mean (i.e., scores $|z|>3.0$ ) [12]. Extreme collinearity was assumed to be indicated by variance inflation factor (VIF) values greater than 10 and tolerance statistics below 0.20 . Univariate normality was assessed with Kolmogorov-Smirnov tests for normality [13], which was followed by visual inspections of the frequency distributions.

\subsection{Main Analyses}

In block 1 , we conducted a linear regression analysis using the pooled data of both surveys. In the regression model, we included the $\mathrm{TpB}$ variables attitude, subjective norm, and perceived behavioral control to predict the participants' intention to eat less meat. As a covariate, frequency of meat consumption was also included in the model. Additionally, we included a dummy variable (coded " 0 " for the survey of 2015; " 1 " for the survey of 2017) to test for a potential effect of time of survey. For the same reason, in block 2 , we further included all respective two-way interaction terms (survey $\times$ attitude; survey $\times$ subjective norm; survey $\times$ perceived behavioral control; survey $\times$ frequency of meat consumption) to test for potentially moderating effects of time of survey. For all analyses and before calculating the respective interaction terms, TpB variables and the covariate were $z$-standardized to reduce multicollinearity [14]. In addition, we conducted separate linear regression analyses for both surveys (2015 and 2017). In those two regression models, we included the TpB variables and the frequency of meat consumption as a covariate to predict the participants' intention to eat less meat.

\section{Results}

\subsection{Descriptive Statistics}

Participants of both surveys $(N=487)$ reported to eat meat regularly $(M=3.77$ days per week, $S D=1.74$, range $=1-7$ days $)$. Their attitude toward eating less meat was $M=4.52(S D=1.32$, range $=1.00-7.00)$, and their subjective norm was $M=3.72(S D=1.01$, range $=1.00-6.67)$. Participants' perceived behavioral control was high $(M=5.83, S D=1.06$, range $=2.25-7.00)$, and their intention to eat less meat was $M=3.97(S D=1.59$, range $=1.00-7.00)$. In Table 1 , descriptive statistics and zero-order correlations for all variables are reported separately for both surveys. 


\subsection{Preliminary Analyses}

An inspection of the frequency distributions of the participants' $z$-scores for all variables included in the main analysis revealed that four participants reported extremely low $z$-scores for perceived behavioral control $(z<-3.14)$. Consequently, these participants were excluded from further data analyses. Checks for extreme collinearity showed that the VIF values for all predictors were well below 10 (all VIF < 1.56) and the tolerance statistics for all predictors were well above 0.20 (all values > 0.64). This indicated that extreme collinearity did not occur in our data. Kolmogorov-Smirnov tests for normality showed that the $\mathrm{TpB}$ scales and the covariates significantly deviated from univariate normality ( $p<0.024$ in all Kolmogorov-Smirnov tests). Visual inspection of the respective frequency distributions revealed that only the scores for perceived behavioral control were severely skewed (skewness $=-0.88$ ), showing that participants were more likely to report high perceived behavioral control regarding the behavior of interest (i.e., eating less meat at least one day a week). To reduce the impact of any possible bias resulting from this negatively skewed distribution, the participants' perceived behavioral control scores were reversed by subtracting each score from the highest score +1 (i.e., $7+1-$ score), as suggested by Tabachnick and Fidell [9]. The reversed scores were then reciprocally transformed (i.e., 1 divided by each participant's reversed perceived behavioral control score). As a result, the interpretation of the mean subjective perceived control score was also reversed.

\subsection{Multivariate Regression Analyses}

The results of the linear multivariate regression models on the intention to eat less meat are provided in Table 2 . For block 1 , results showed statistically significant effects of the participants' attitude toward eating less meat $(\beta=0.67, p<0.001)$ and their respective subjective norm $(\beta=0.18$, $p<0.001$ ), but the results did not show a statistically significant effect for the participants' perceived behavioral control $(\beta=0.04, p=0.292)$. The participants' frequency of meat consumption significantly predicted their intention to eat less meat $(\beta=-0.06, p=0.047)$.

Further, results revealed that the time of one's participation in the survey had a statistically significant effect on their intention to eat less meat ( $\beta=0.08, p=0.016$ ). Results for block 2 , however, showed that all respective two-way interactions between the time of the survey and the $\mathrm{TpB}$ variables as well as the covariate (i.e., survey $\times$ attitude; survey $\times$ subjective norm; survey $\times$ perceived behavioral control; survey $\times$ frequency of meat consumption) were statistically insignificant (all $p s>0.434$ ). These results indicated that the time of the survey did not moderate the effects of the $\mathrm{TpB}$ variables on one's intention to eat less meat.

When data were analyzed for both surveys (2015 and 2017) separately, results of the respective linear regression models revealed similar results as block 1 of the first model. For both samples, $R$ for the entire regression model was significantly different from zero $(2015: F(4,249)=74.97, p<0.001$ vs. 2017: $F(4,224)=93.61, p<0.001)$. For the 2015 survey, the results showed statistically significant effects of the participants' attitude toward eating less meat $(\beta=0.66, p<0.001)$ and their respective subjective norm $(\beta=0.16, p=0.001)$, but did not show statistically significant effects for the participants' perceived behavioral control $(\beta=0.06, p=0.212)$. However, for the sample of the 2015 survey, the participants' frequency of meat consumption did not significantly predict their intention to eat less meat $(\beta=-0.04$, $p=0.388$ ). For the 2017 survey, the results also revealed the statistically significant main effects of the participants' attitude toward eating less meat $(\beta=0.67, p<0.001)$ and their respective subjective norm $(\beta=0.18, p<0.001)$, but did not show statistically significant effects of the participants' perceived behavioral control $(\beta=0.02, p=0.667)$. For the sample of the 2017 survey, the participants' frequency of meat consumption significantly predicted their intention to eat less meat $(b=-0.08, p=0.042)$. 
Table 1. Descriptive statistics, internal consistencies (Cronbach's $\alpha$ ), and zero-order correlations.

\begin{tabular}{|c|c|c|c|c|c|c|c|}
\hline & $\mathbf{M}$ & SD & $\alpha$ & (1) & (2) & (3) & (4) \\
\hline \multicolumn{8}{|l|}{ Survey $2015(N=256)$} \\
\hline (1) Attitude & 4.64 & 1.26 & 0.88 & & & & \\
\hline (2) Subjective norm & 3.69 & 1.00 & 0.68 & $0.46^{* *}$ & & & \\
\hline (3) Perceived behavioral control & 6.10 & 0.92 & 0.58 & 0.31 ** & -0.02 & & \\
\hline (4) Intention & 3.95 & 1.51 & 0.86 & $0.71^{* *}$ & $0.45^{* *}$ & $0.13^{*}$ & \\
\hline (5) Frequency of meat consumption & 3.58 & 1.68 & & $-0.29^{* *}$ & -0.11 & $-0.15^{*}$ & $-0.23^{* *}$ \\
\hline \multicolumn{8}{|l|}{ Survey $2017(N=231)$} \\
\hline (1) Attitude & 4.38 & 1.38 & 0.82 & & & & \\
\hline (2) Subjective norm & 3.74 & 1.03 & 0.61 & $0.54 * *$ & & & \\
\hline (3) Perceived behavioral control & 5.53 & 1.12 & 0.45 & $0.38^{* *}$ & 0.11 & & \\
\hline (4) Intention & 4.00 & 1.68 & 0.85 & $0.77^{* *}$ & $0.55^{* *}$ & 0.26 ** & \\
\hline (5) Frequency of meat consumption & 3.98 & 1.79 & & -0.11 & -0.06 & -0.08 & $-0.16^{*}$ \\
\hline
\end{tabular}


Table 2. Hierarchical regression analysis regressing mean intention score on TpB variables (attitude, subjective norm, and perceived behavioral control), frequency of meat consumption, time of survey, and their interaction terms considering frequency of meat consumption.

\begin{tabular}{|c|c|c|c|c|c|c|}
\hline \multirow{2}{*}{ Block and Predictors } & \multirow{2}{*}{$b$} & \multicolumn{2}{|c|}{$95 \% C I$ for $b$} & \multirow{2}{*}{$S E \boldsymbol{b}$} & \multirow{2}{*}{$\beta$} & \multirow{2}{*}{$p$} \\
\hline & & $L L$ & $U L$ & & & \\
\hline \multicolumn{7}{|l|}{ Block 1} \\
\hline Constant & -0.07 & -0.16 & 0.01 & 0.04 & & 0.076 \\
\hline Attitude $^{a}$ & 0.67 & 0.60 & 0.75 & 0.04 & 0.67 & 0.000 \\
\hline Subjective norm ${ }^{a}$ & 0.18 & 0.11 & 0.25 & 0.04 & 0.18 & 0.000 \\
\hline Perceived behavioral control a & 0.04 & -0.03 & 0.10 & 0.03 & 0.04 & 0.292 \\
\hline Frequency of meat consumption ${ }^{a}$ & -0.06 & -0.12 & 0.00 & 0.03 & -0.06 & 0.047 \\
\hline \multirow[t]{2}{*}{ Survey ${ }^{b}$} & 0.15 & 0.03 & 0.27 & 0.06 & 0.08 & 0.016 \\
\hline & \multicolumn{6}{|c|}{$R^{2}=0.586, R_{\text {adjusted }}^{2}=0.582, F(5,477)=135.00, p<0.001$} \\
\hline \multicolumn{7}{|l|}{ Block 2} \\
\hline Constant & 0.04 & -0.24 & 0.32 & 0.14 & & 0.771 \\
\hline Attitude $^{\text {a }}$ & 0.66 & 0.56 & 0.77 & 0.05 & 0.65 & 0.000 \\
\hline Subjective norm $^{a}$ & 0.16 & 0.06 & 0.25 & 0.05 & 0.16 & 0.001 \\
\hline Perceived behavioral control $^{\mathrm{a}}$ & 0.07 & -0.04 & 0.17 & 0.05 & 0.06 & 0.213 \\
\hline Frequency of meat consumption ${ }^{a}$ & 0.01 & -0.18 & 0.20 & 0.10 & 0.01 & 0.923 \\
\hline Survey $\mathrm{b}$ & 0.25 & -0.04 & 0.54 & 0.15 & 0.12 & 0.090 \\
\hline Survey ${ }^{b} \times$ Attitude $^{a}$ & 0.03 & -0.12 & 0.17 & 0.08 & 0.02 & 0.735 \\
\hline Survey ${ }^{\mathrm{b}} \times$ Subjective norm $^{\mathrm{a}}$ & 0.03 & -0.10 & 0.17 & 0.07 & 0.02 & 0.622 \\
\hline Survey ${ }^{\mathrm{b}} \times$ Perceived behavioral control $^{\mathrm{a}}$ & -0.05 & -0.19 & 0.09 & 0.07 & -0.03 & 0.499 \\
\hline \multirow[t]{2}{*}{ Survey ${ }^{b} \times$ Frequency of meat consumption ${ }^{a}$} & -0.03 & -0.10 & 0.04 & 0.04 & -0.10 & 0.435 \\
\hline & \multicolumn{6}{|c|}{$R^{2}=0.588, R_{\text {adjusted }}^{2}=0.580, F(9,473)=75.01, p<0.001$} \\
\hline
\end{tabular}

Note: $N=483 .{ }^{\text {a }}$ Variables were $z$-standardized. ${ }^{\mathrm{b}}$ Coding: $0=$ survey $2015 ; 1=$ survey 2017. $C I=$ confidence interval; $L L=$ lower limit; $U L=$ upper limit. 


\section{Discussion}

We investigated the predictive power of $\mathrm{TpB}$ [3] for the intention to eat less meat using the data from two recent surveys (i.e., 2015 and 2017) that were conducted in Switzerland. Based on the assumptions of the $\mathrm{TpB}$ and previous research from the 1990s [5,6], we assumed that the individuals' intention to eat less meat would be predicted most strongly by their respective attitude but not by their perceived behavioral control. For example, Sparks et al. [6] found one's intention to reduce meat consumption to be predicted mainly by the individual's attitude $(\beta=0.69, p<0.001)$. Similar results were obtained by Harland et al. [5] who found a statistically significant effect of the individuals' attitude toward reducing meat consumption $(\beta=0.62, p<0.001)$. In both previous studies from the 1990s, perceived behavioral control proved to be statistically irrelevant in predicting the individuals' intention (Harland et al.: $\beta=0.06$, ns.; Sparks et al.: $\beta=-0.01$, non-significant). In line with these previous studies, in the pooled sample from both surveys (2015 and 2017), we found the individuals' intention toward eating less meat to be predicted most strongly by the individuals' respective attitude $(\beta=0.67, p<0.001)$, whereas perceived behavioral control was not a statistically relevant predictor ( $\beta=0.04, p=0.292)$. The same pattern was found when we analyzed data for both surveys separately (2015 and 2017).

Harland et al. [5] found that the individuals' subjective norm predicted the individuals' intention to reduce meat consumption to a much lesser amount than the individuals' attitude $(\beta=0.14, p<0.010)$, whereas Sparks et al. [6] found no respective effect of the individuals' subjective norm at all ( $\beta=0.05$, non-significant). In contrast to these studies from the 1990s, we had expected a heightened influence of the individuals' subjective norm due to recent trends (e.g., veganism [7]) and heightened accessibility of information about the damaging effects of domestic meat consumption (e.g., [8]). However, we found similar levels of the individuals' subjective norm $(\beta=0.18, p<0.001)$ as Harland et al. had in 1999 . We found similar results once more when analyzing data from both surveys separately (2015: $\beta=0.16$, $p=0.001$ vs. 2017: $\beta=0.18, p<0.001$ ). Thus, despite more recent trends and the heightened accessibility of information about the damaging effects of domestic meat consumption, perceived social pressure to eat less meat has not increased accordingly.

The present study was limited as we did not measure the individuals' actual eating behavior. Moreover, our sample was limited to students and employees. Hence, future studies should assess actual meat consumption behavior and include additional consumer groups.

\section{Conclusions}

As meat consumption significantly contributes to environmental damage [1], a reduction in domestic meat consumption is regarded as sustainable behavior [2]. The results of the present research imply that sustainable consumption is most likely to be achieved when consumers change their attitudes.

Author Contributions: A.K. analyzed and interpreted the data and prepared the draft manuscript. A.B. conceptualized the study, managed the data collection and data entry, prepared the data for the analyses, and provided critical comments on the manuscript draft. All authors have read and agreed to the published version of the manuscript.

Funding: This research received no external funding.

Conflicts of Interest: The authors declare no conflict of interest.

\section{References}

1. Pohjolainen, P.; Tapio, P.; Vinnari, M.; Jokinen, P.; Räsänen, P. Consumer consciousness on meat and the environment-Exploring differences. Appetite 2016, 101, 37-45. [CrossRef] [PubMed]

2. Hedenus, F.; Wirsenius, S.; Johansson, D.J.A. The importance of reduced meat and dairy consumption for meeting stringent climate change targets. Clim. Chang. 2014, 124, 79-91. [CrossRef]

3. Ajzen, I. The theory of planned behavior. Organ. Behav. Hum. Decis. Process. 1991, 50, 179-211. [CrossRef] 
4. Armitage, C.J.; Conner, M. Efficacy of the theory of planned behavior: A meta-analytical review. Br. J. Soc. Psychol. 2001, 40, 471-499. [CrossRef] [PubMed]

5. Harland, P.; Staats, H.; Wilke, H.A.M. Explaining proenvironmental intention and behavior by personal norms and the theory of planned behavior. J. Appl. Soc. Psychol. 1999, 29, 2505-2528. [CrossRef]

6. Sparks, P.; Guthrie, C.A.; Shepherd, R. The dimensional structure of the perceived behavioral control construct. J. Appl. Soc. Psychol. 1997, 27, 418-438. [CrossRef]

7. Schüpbach, R.; Wegmüller, R.; Berguerand, C.; Bui, M.; Herter-Aeberli, I. Micronutrient status and intake in omnivores, vegetarians and vegans in Switzerland. Eur. J. Nutr. 2017, 56, 283-293. [CrossRef] [PubMed]

8. Springmann, M.; Godfray, H.C.J.; Rayner, M.; Scarborough, P. Analysis and valuation of the health and climate change cobenefits of dietary changes. Proc. Natl. Acad. Sci. USA 2016, 113, 15. [CrossRef] [PubMed]

9. Tabachnick, B.G.; Fidell, L.S. Using Multivariate Statistics, 5th ed.; Allyn and Bacon: Boston, MA, USA, 2007.

10. Swiss Federal Council. Environment Switzerland 2015: Report of the Federal Council. 2015. Available online: https://www.bafu.admin.ch/bafu/en/home/state/publications-on-the-state-of-the-environment/ environment-switzerland-2015.html (accessed on 30 March 2019).

11. Ajzen, I. Constructing a TpB Questionnaire: Conceptual and Methodological Considerations. 2006. Available online: http://www.people.umass.edu/aizen/pdf/tpb.measurement.pdf (accessed on 31 May 2015).

12. Field, A. Discovering Statistics Using IBM SPSS Statistics, 5th ed.; Sage: Thousand Oaks, CA, USA, 2018.

13. Lilliefors, H.W. On the Kolmogorov-Smirnov test for normality with mean and variance unknown. J. Am. Stat. Assoc. 1967, 62, 399-402. [CrossRef]

14. Aiken, L.S.; West, S.G. Multiple Regression: Testing and Interpreting Interactions; Sage: Thousand Oaks, CA, USA, 1991.

(C) 2020 by the authors. Licensee MDPI, Basel, Switzerland. This article is an open access article distributed under the terms and conditions of the Creative Commons Attribution (CC BY) license (http://creativecommons.org/licenses/by/4.0/). 